\title{
Assessment of Indoor Environmental Quality of Mymensingh Medical College Hospital
}

\author{
Nurun Nahar Nijhum ${ }^{1}$, Md. Shahadat Hossen ${ }^{2 *}$, Rehana Khatun ${ }^{2}$ \\ ${ }^{l}$ MS student, Department of Environmental Science, Bangladesh Agricultural University, Mymensingh. \\ ${ }^{2}$ Professor, Department of Environmental Science, Bangladesh Agricultural University, Mymensingh
}

*Corresponding Author: Md. Shahadat Hossen, Department of Environmental Science, Bangladesh

Agricultural University, Mymensingh, Bangladesh

\begin{abstract}
A study was carried out during the monsoon period (July-August), 2018 in Mymensingh Medical College Hospital (MMCH) for the assessment of indoor environmental quality (IEQ). Three IEQ parameters (thermal quality, sound quality and light quality) were measured in 30 wards of the two buildings of MMCH. Among the 400 selected respondents; 157 were patients, 183 were visitors and 60 were staffs. It has been observed that the average temperature of $M M C H$ was $31.5^{\circ} \mathrm{C}$. Occupants' perception regarding thermal comfort varied from neutral (patients and visitors) to hot (staffs) and mostly satisfied with that condition. The study revealed that humidity ranged from $66 \%$ to $84 \%$ and the occupant's perception of the humidity was neutral (patients) and high (visitors, staffs). Lighting quality varied greatly on different wards though occupants were satisfied with the quality. Noise intensity of MMCH was 55.25dB. Although it was higher than national standards patients and visitors reported the noise level was neutral, where staffs indicated as noisy. A socioeconomic condition of the respondents might have an influence on the sensation of indoor environmental quality.
\end{abstract}

Keywords: Indoor Environmental Quality, Medical College Hospital, Thermal Quality, Acoustic Quality, Lighting Quality.

\section{INTRODUCTION}

Hospitals are a place where doctors, workers, and patients have to stay long durations in indoor environments where they may be affected by the levels of indoor environmental pollutants. Indoor Environmental Quality (IEQ) is general indicator of the quality of conditions inside that affect the human life inside a building. Physical, chemical biological factors include indoor air quality (IAQ), lighting, thermal comfort, acoustics, drinking water, ergonomics, electromagnetic radiation, and many related factors determine the IEQ of any given building. Enhanced environmental quality can improve the quality of life of the occupants and help decrease the occurrence of sick building syndrome and building related illness. An imbalance of IEQ can give a negative impact to facilities, building and occupants as it affects to the health quality of occupant and also affect the hearing and listening process (Sulaiman et al., 2013). IEQ emphasis on the significant impact exposure of occupants to air quality, thermal comfort, visual comfort and acoustic problems (ASHRAE, 2016).

Indoor air quality in hospital is of great concern for patients and medical personnel, thus mandating the use of efficient heating, ventilating and air-conditioning (HVAC) installations control indoor environmental quality (IEQ) and aseptic conditions, and secure healthy, safe and suitable indoor air quality (IAQ), for surgeons and medical staff, and of course, the patients (Balaras et al., 2007; Dascalaki et al., 2008). It includes ventilation system, surfaces, clothing, and chemical parameters (Anderson et al., 1998; Wood head et al., 2002; Humphreys and Taylor, 2002; Panni and Corn, 2002; Mierdi et al., 2003).

Thermal comfort is, "the range of climatic conditions within which a majority of the people would not feel discomfort either of heat or cold" (MNRE, 2016). Thermal conditions within existing government hospital buildings play a critical role where patients spend time which influences their health comfort and wellbeing (Kushairi et al., 2015; ASHRAE, 2016). Although thermal comfort is subjective but the environmental factors (i.e. air temperature, air velocity, humidity, radiant temperature, and relative humidity), and human factors (i.e clothing and metabolic heat) influences its sesation (Skoog et al., 
2005; Holm, 2005; Pfafferott et al., 2005).

The determinant of lighting levels is visual comfort and it is defined as satisfaction of visual system and the absence of glare (Dubois et al., 2007). Lighting allows us to see things and perform activities and also affects human beings psychologically and physiologically.

Light has an important role in reducing depression, decreasing fatigue (Ulrich et al., 2004) and low light during the day and too much light at night may affect circadian rhythms and hence influence human mood and health, increasing the risk of hypertension and diabetes (Gordijn, 2012; Lee, 1997; Sharkey, 2013). Incorporating light into healthcare settings can be beneficial for patients as well as the staff who work there and are linked to reduced medication-dispensing errors in pharmacies (Joseph, 2006).

Noise is an undesirable sound (Dara, 1993; ASHRAE, 2016). The acoustic environment can cause hearing loss, stress, alter sleep patterns, and affect heart rate based on other IEQ co-factors (ASHRAE, 2016). In inside the building, noise from HVAC, light and other sources can cause discomfort, annoyance and result in headaches and fatigue (Prakash, 2005), in some cases perpetual and chronic exposure to excessive sound can lead to permanent hearing loss (Bruce et al., 1998). In the context of a healthcare facility, external noise includes traffic, deliveries and sirens. Internal noise can include ventilator noise and alarms, suctioning, heart monitor alarms, nebulizers, pulse oximeter tones and alarms, telephones ringing, air conditioning, television, radio, banging, rubbish bin or trolley noises, intercoms, staff bleeps, talking (staff, nurses), visitors, fellow-patients, and general activities (AS/NZS 2000; Megan and Pearson, 2011).

IEQ was carried out in different building types such as educational, healthcare, residential, office etc in all over the world. There has no research work on IEQ of hospitals in Bangladesh. Therefore, the present work was conducted to assess IEQ of MMCH.

\section{Materials AND Methods}

\subsection{Study Area}

The research work was conducted in Mymensingh Medical College Hospital, a public medical college hospital situated at Charpara $\left(24.7427^{\circ} \mathrm{N}, 90.4096^{\circ} \mathrm{E}\right)$ on the eastern part of Mymensingh town and beside the Dhaka-Mymensingh highway.

\subsection{Data Collection}

The data were collected in the period July-August 2018 from a cross-sectional study conducted in Bangladesh. A combination of a subjective and objective measurements were done. A questionnaire survey was conducted using structured questionnaire with an explanation to the purpose and procedure of the study. This paper focuses mainly on responses regarding occupant's general satisfaction and perception of indoor environment quality (IEQ): thermal, acoustic, and daylight quality (Table 1). There were 30 wards in Mymensingh Medical College hospital from where 400 respodent (Patients 157, Visitors 183, Staffs 60) were randomly selected for this survey. In situ measurements at selected hospital wards were conducted using digital hygrometer (temperature and humidity), light meter (light intensity) and sound level meter (noise level) during the questionnaire data collection period.

Table1.Variables and survey questions, answers and assigned values

\begin{tabular}{|c|c|c|}
\hline Variable & Question & Measurement \\
\hline Thermal Quality & $\begin{array}{l}\text { How do you perceive thermal comfort } \\
\text { in your ward? }\end{array}$ & $\begin{array}{c}\text { Very hot }(+2) \text { Hot } \\
(+1) \\
\text { Neutral }(0) \\
\text { Cool }(-1) \\
\text { Very cool }(-2)\end{array}$ \\
\hline Perception of humidity & $\begin{array}{l}\text { How do you perceive humidity in your } \\
\text { ward? }\end{array}$ & $\begin{array}{c}\text { Very high }(+2) \\
\text { High }(+1) \\
\text { Neutral }(0) \\
\text { low }(-1) \\
\text { Very low }(-2)\end{array}$ \\
\hline $\begin{array}{c}\text { Perception of light } \\
\text { quality }\end{array}$ & How do you perceive daylight quality & Very $\operatorname{Dim}(-2)$ \\
\hline
\end{tabular}




\begin{tabular}{|c|c|c|}
\hline & in your ward? & Dim $(-1)$ \\
& & Neutral $(0)$ \\
& & Bright $(+1)$ \\
& & Very Bright $(+2)$ \\
\hline Perception of acoustic quality & How do you perceive noise level in & Very Noisy (-2) \\
& your ward? & Very Noisy (-1) \\
& & Neutral $(0)$ \\
& & Silent $(+1)$ \\
(Thermal/humidity/light/noise) & How do you describe satisfaction with & Very Quiet $(+2)$ \\
& your ward for & Very Dissatisfied $(-2)$ \\
& (Thermal/humidity/light/noise) $?$ & Dissatisfied $(-1)$ \\
& & Neutral $(0)$ \\
& & Satisfied $(+1)$ \\
& & Very Satisfied $(+2)$ \\
\hline
\end{tabular}

\subsection{Data Analysis}

The data from the questionnaire survey were analyzed using statistical software IBM SPSS Statistics 22.0

Table1. Measured IEQ parameters of Mymensingh Medical College Hospital

\begin{tabular}{|c|c|c|c|c|}
\hline \multirow{2}{*}{ Variables } & \multicolumn{4}{|c|}{ IEQ Elements } \\
\cline { 2 - 5 } & Temperature $\left({ }^{\circ} \mathbf{C}\right)$ & Humidity $(\%)$ & $\begin{array}{c}\text { Sound Intensity } \\
(\mathbf{d b})\end{array}$ & $\begin{array}{c}\text { Light Quality } \\
(\mathbf{L u x})\end{array}$ \\
\hline Maximum & 36.4 & 87 & 71 & 815 \\
\hline Minimum & 22.2 & 66 & 48 & 40 \\
\hline Mean & 31.5 & 76.7 & 55.6 & 5.77 \\
\hline $\begin{array}{c}\text { Standard Deviation } \\
\text { (SD) }\end{array}$ & 1.87 & 3.61 & 4.36 & \\
\hline
\end{tabular}

\section{RESULTS AND DISCUSSION}

\subsection{Thermal Quality}

Thermal quality and satisfaction with the thermal environment is important for occupants of an indoor environment because it influences productivity and health.

\subsubsection{Temperature}

Table 1 shows the temperature among of 30 wards ranged from 22.2 to $36.4 \square \mathrm{C}$ with mean $31.5 \square \mathrm{C}$ (Table 1). That is acceptable for the health of MMCH occupants as ASHRAE Standard (2013) recommended the thermal environmental conditions for human occupancy could range from between approximately $19.44^{\circ} \mathrm{C}$ and $34.44^{\circ} \mathrm{C}$ (ASHRAE, 2013). Though the temperature level of MMCH was acceptable majority of staffs perception of thermal was hot $(61.7 \%)$ whereas as patients $(58.7 \%)$ and visitors $(33.3 \%$ ) expressed it as neutral (Figure 1a). Patients and visitors perception varied from cool to very hot but staff perception varied from neutral to very hot. Around $45.9 \%$ patients were satisfied with the thermal comfort of $\mathrm{MMCH}, 25.4 \%$ of the patients were dissatisfied with the thermal comfort and $28.6 \%$ rated it as neutral. Where, $54.6 \%$ visitors satisfied and $12 \%$ rated as neutral and around $33.3 \%$ visitors rated it as dissatisfied. Majority of staffs $(65 \%)$ stated the thermal comfort of Indoor MMCH as satisfied and around 3.3\% stated it was neutral (Figure 1b).

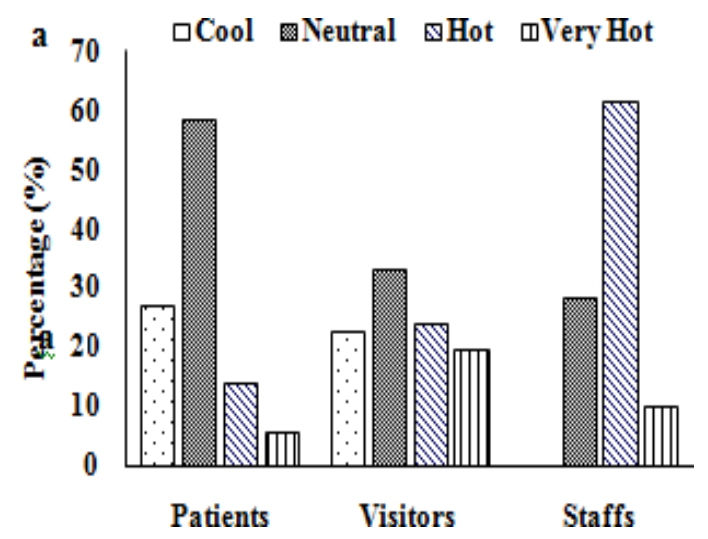




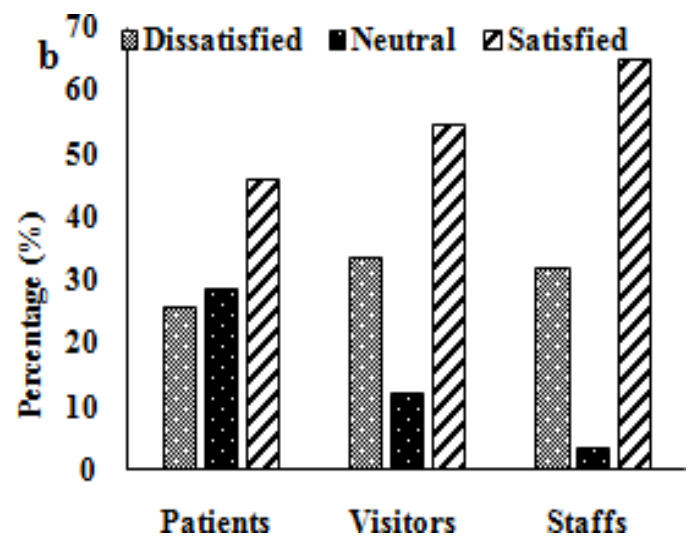

Figure1. Occupants Perception (A); And Satisfaction Level (B) Of Temperature In MMCH

\subsubsection{Humidity}

The study shows that, the average humidity of MMCH was $76.13 \%$ with the ranged from $66 \%$ to $87 \%$ (Table 1). With the comparison of ASHRAE Standards amounts of humidity were on accepted for human occupancy on indoor environment (ASHRAE Standard, 2016; ASHRAE Standard, 2013). ASHRAE Standard (2016) recommended the relative humidity ranged from $65 \%$ to $80 \%$ in indoor building (ASHRAE Standard, 2013).

It was found that, around $54.1 \%$ patients stated the humidity of indoor $\mathrm{MMCH}$ was neutral, $26.4 \%$ as low, $20.4 \%$ as high, and $6 \%$ as very low and $1.3 \%$ was very high. Among the visitors, $45.9 \%$ stated it was high, $32.8 \%$ as low, $16.4 \%$ as neutral, $2.7 \%$ responded as very high and $2.2 \%$ was very low. Majority of the respondents of staff (66.7\%) stated it was high, $13.3 \%$ neutral, $11.7 \%$ as low, $3.3 \%$ as very low and $13.3 \%$ as very high(Figure $2 a$ ). Figure $2 b$ shows the satisfaction level of relative humidity on MMCH. Here, majority of patients $(48.4 \%$ ) was satisfied, whereas $27.4 \%$ was neutral and $24.2 \%$ was dissatisfied for humidity level. Majority of visitors (56.8\%) was satisfied with the relative humidity and $32.8 \%$ stated as dissatisfied, where $10.4 \%$ rated it as neutral. Among the staffs; $40 \%$ was satisfied, $40 \%$ as dissatisfied and $20 \%$ expressed as neutral for humidity level.

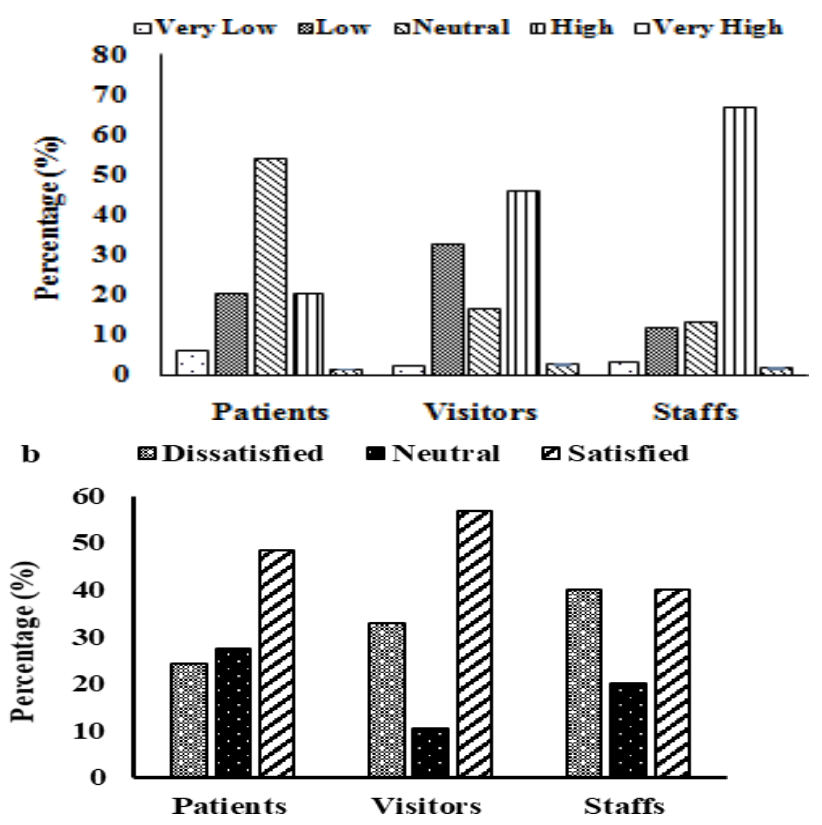

Figure2. Occupants Perception (A); And Satisfaction Level (B) Of Humidity In MMCH

\subsection{Acoustic Quality}

Acoustic quality belongs to subjective feeling, noise of surrounding get on people's nerve even if the noise does not exceed the standard level. Sound intensity of MMCH varied from $48 \mathrm{~dB}$ to $71 \mathrm{~dB}$ with an average of $55.6 \mathrm{~dB}$ which exceed acceptable limit from department of environment (DoE). From DoE 
recommendations, where the acceptable level for day time $(6 \mathrm{am}-9 \mathrm{pm})$ is $45 \mathrm{~dB}$ and for night time (9pm$6 \mathrm{am})$ as $35 \mathrm{~dB}$ (DoE, 2000).Most of sound intensity was related to human crowdness.
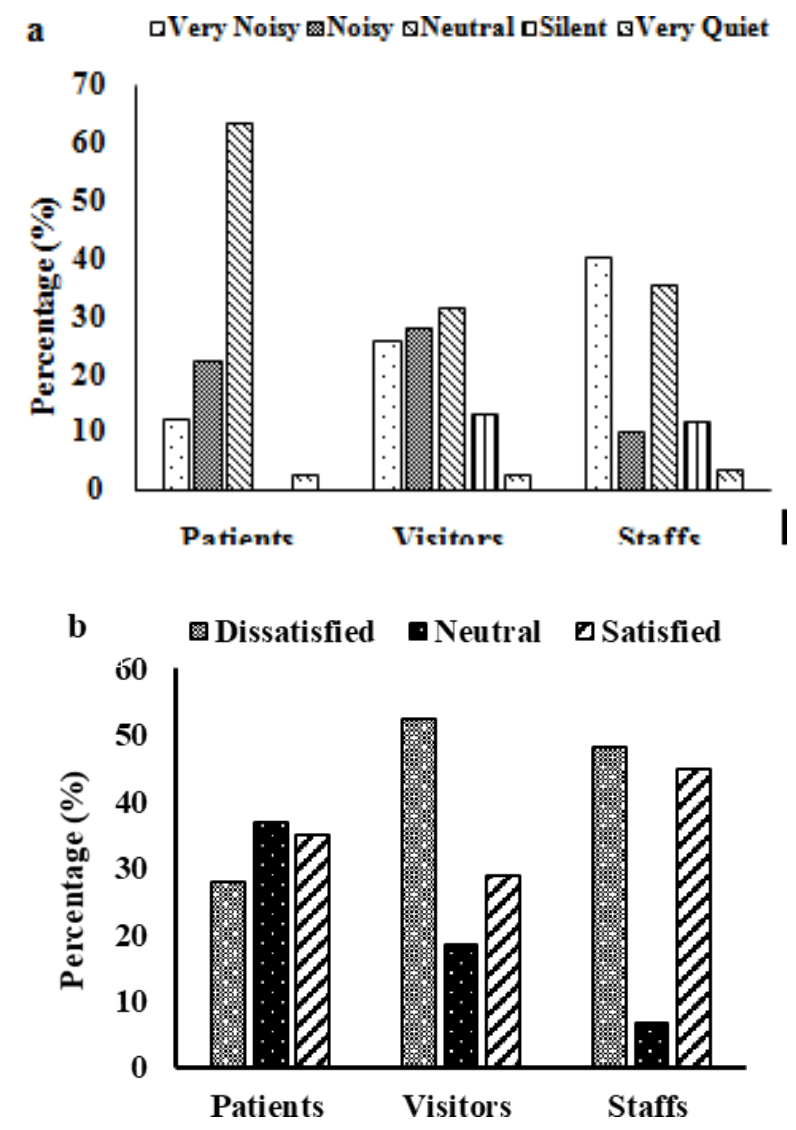

Figure3. Occupants perception (a); and satisfaction level (b) of noise intensity in MMCH

The study found that, majority of patients $(63.1 \%)$ and visitors $(31.1 \%)$ were rated the noise comfort of $\mathrm{MMCH}$ was neutral. Around $22.3 \%$ patients indicated it as noisy, $12.1 \%$ as very noisy. Besides, among the visitors around $27.9 \%$ stated it was noisy, $25.7 \%$ about very noisy, and $13.1 \%$ rated it as silent. Majority of staffs (40\%) expressed it as very noisy, 35\% as neutral, $11.7 \%$ agreed for silent and $10 \%$ as noisy. Though the noise level of MMCH was high from the acceptable limits of DoE, but majority of patients and visitors rated it as neutral. But the respondents of staffs indicated it as very noisy (Figure $3 a$ ). But the satisfaction with noise (Figure 3b) represents different features on the respondents, where $36.9 \%$ patients stated the noise level of $\mathrm{MMCH}$ was neutral, $35.1 \%$ were satisfied and $28 \%$ opinioned as dissatisfied. Majority of visitors (52.4\%) stated it as dissatisfied, $28.9 \%$ agreed it as satisfied, $18.6 \%$ stated it as neutral. Among the staffs respondents $48.3 \%$ reported as dissatisfied, $45 \%$ as satisfied and $6.7 \%$ were rated it as neutral.

\subsection{Lighting Quality}

Lighting Quality as lighting can change the mood of people and affected their psychology of occupants of indoor environment.

Light intensity of MMCH varied from 40 to 815 lux in different wards with an average of 178.2 lux. Mehrotra et al. (2015) asserted that, illuminance for the general wards and rooms for the patients would be, 100 lux. Perceptional level of light intensity was found that $85.4 \%$ of patients, $84.7 \%$ of visitors and $88.3 \%$ of staffs were expressed as the light intensity of $\mathrm{MMCH}$ was neutral. Minority percentages as $5.7 \%$ patients, $6 \%$ of visitors and $3.3 \%$ of staffs responded for bright $8.9 \%$ of patients, $9.3 \%$ of visitors, and $8.3 \%$ of staffs were rated it as $\operatorname{dim}$ (Figure $4 \mathrm{a}$ ). Figure $4 \mathrm{~b}$ revealed that, the satisfaction of visual comfort of MMCH. It shows that, the occupants were satisfied with the visual comforts in the wards of MMCH. 91.4\% patients reported visual comfort of MMCH was satisfied, only $2.5 \%$ of the patients stated it was dissatisfied, and 5.7\% expressed the visual comfort was neutral. $84.2 \%$ visitors indicated as satisfied, $10.9 \%$ stated it as neutral and $4.9 \%$ stated it as dissatisfied. Majority of the respondents of staff $(73.3 \%)$ stated the visual comfort of $\mathrm{MMCH}$ was 
satisfied and around $6.7 \%$ dissatisfied with the visual comfort, and around $20 \%$ stated as neutral.

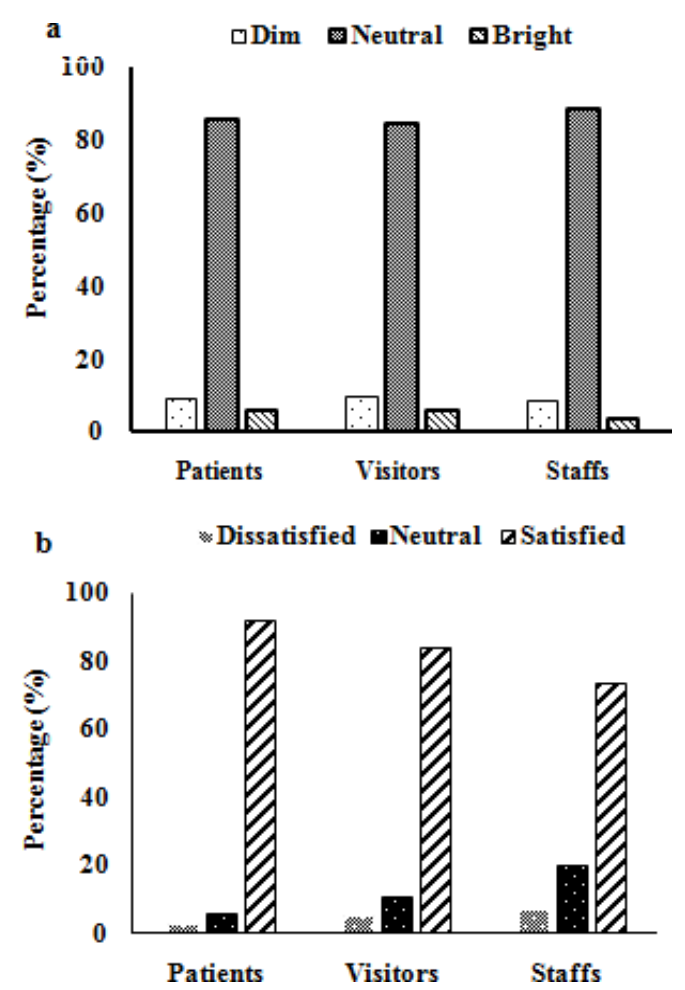

Figure4. Occupants perception (a); and satisfaction level (b) of light intensity in MMCH

\section{CONCLUSION}

Among the studied IEQ factors, temperature and humidity levels were within limits. Although noise level was quite high, most of the occupants rated it as neutral. Occupants were also satisfied with light intensity upon its large variation. A little variation was observed in sensation and objective measurements where Patients and visitors rated their sensation systematically lower than predicted by objective measurements, and with staffs sensation. Socioeconomic condition might have an influence on sensation of indoor environmental quality.

\section{REFERENCES}

[1] Andersen BM, Roed RT, Solheim N, Levy F, Bratteberg A, Kristoffersen K (1998). Air quality and microbiologic contamination in operating theatres. Tidsskr Nor Laegeforen 118 3148-3151.

[2] ASHRAE (2013). American Society of Heating, Refrigerating and Air Conditioning Engineers, ASHRAE Standards 55-2013, Atlanta, USA.

[3] ASHRAE (2016). American Society of Heating, Refrigerating and Air Conditioning Engineers, ASHRAE Standards 62.1- 2016, Atlanta, USA.

[4] AS/NZS (2000). 2107Acoustics - Recommended design sound levels and reverberation times for building interiors, Australian Standards/ Newzealand Standards.

[5] Balaras CA, Dascalaki EG, Gaglia AG (2007). HVAC and indoor thermal conditions in hospital operating rooms. Energy and Buildings 39 454-70.

[6] Bruce RD, Bommer AS, Moritz CT (1998). The Occupational Environment- Its Evaluation and

[7] Control. American Industrial Hygiene Association, Fairfax, Virginia. pp. 425-489.

[8] Dara SS (1993). A textbook of Environmental Chemistry and Environmental Pollution. S. Chand \& Company Limited, New Delhi, India. pp. 149.

[9] Dascalaki EG, Lagoudi A, Balaras CA, Gaglia AG (2008). Air Quality in hospital operating rooms. Building and Environment 43 1945-1952.

[10] DoE (2000). Department of Environment, National Action Plan for Bangladesh on Control and Prevention of Air Pollution and its Likely Transboundary Effects, Government of the People of Bangladesh, Dhaka, Bangladesh.

[11] Dubois C, Demers C, Potvin A (2007). The Influence of Day lighting on Occupants: Comfort and Diversity of Luminous Ambiences in Architecture. In Proceedings of the Solar Conference, American Solar Energy Society; American Institute of Architects. 
[1] Gordijn MC, Mannetje D, Meesters Y. (2012). The effects of blue-enriched light treatment compared to standard light treatment in seasonal affective disorder. J Affect Disord. 136: 72-80.

[2] Holm FAD (2005). Engelbrecht, Practical choice of thermal comfort scale and range in naturally ventilated buildings in South Africa. Journal of the South African Institution of Civil Engineering 47 9-14.

[3] Humphreys H, Taylor EW (2002) Operating theatre ventilation standards and the risk of postoperative infection. Journal of Hospital Infection 50 85-90.

[4] Joseph A (2006). The Impact of Light on Outcomes in Healthcare Settings, PhD Thesis, the Center for Health Design, Concord, CA.

[5] Kushairi AAA, Mahyuddin N, Adnan E, Sulaiman R (2015). Perceptions on Thermal Comfort in General Wards for Malaysian Hospitals. Journal of Building Performance 615.

[6] Megan S Pearson A (2011). Effects of noise pollution on healthcare staff and patients, A white paper 1-6.

[7] Mehrotra S, Basukala S, Devarakonda S (2015). Effective Lighting Design Standards Impacting Patient Care: A Systems Approach. Journal of Biosciences and Medicines 3 54-61.

[8] Mierdl S, Byhahn C, Abdel-Rahman U, Matheis G, Westphal K (2003). Occupational exposure to inhalational anesthetics during cardiac surgery on cardiopulmonary bypass. The Annals of Thoracic Surgery 75 1924-1927.

[9] MNRE (2016). Ministry of New and Renewable Energy, Government of India Solar Energy, New Delhi, India.

[10] Panni MK, Corn SB (2002). The use of a uniquely designed anesthetic scavenging hood to reduce operating room anesthetic gas contamination during general anesthesia. Anesthesia and Analgesia 95 656-660.

[11] Pfafferott J, Herkel S, Wapler J, (2005). Thermal building behaviour in summer: long term data evaluation using simplified models, Energy and Buildings 37 844-852.

[12] Prakash P (2005). Effect of Indoor Environmental Quality on Occupant's perception of performance: A comparative study, Masters Thesis, Department of Interior Design, University of Florida, USA.

[13] Sharkey KM, Pearlstein TB, Carskadon MA. (2013). Cirdadian phase shift and mood across perinatal period in women with a history of major depressive disorder: A preliminary report. J Affect Disord. 150:1103-8.

[14] Skoog J, Fransson N, Jagemar L (2005). Thermal environment in Swedish hospitals: summer and winter measurements, Energy and Buildings 37 872-877.

[15] Sulaiman MA, Wan Yusoff WZ, Pawi S, Wan Kamarudin WN (2013). Indoor Environmental Quality (IEQ) of Higher Education Institutions (HEIs): A User Perception Survey. Journal of Clean Energy Technologies 1(4) 318-321.

[16] Ulrich R.S., Zimring C, Joseph A., Quan X., Choudhary R., (2004). The role of the physical environment in the hospital of the 21st century: A once-in-a-lifetime opportunity, Research, The Center for Health Design, Concord, Canada.

[17] Woodhead K, Taylor EW, Bannister G, Chesworth T, Hoffman P, Humphreys H (2002). Behaviours and rituals in the operating theatre. Journal of Hospital Infection 51 241-255.

Citation: Md. Shahadat Hossen,et.al., " Assessment of Indoor Environmental Quality of Mymensingh Medical College Hospital", International Journal of Research in Environmental Science (IJRES), vol. 6, no. 1, pp.34-40, 2020. Available: DOI: http://dx.doi.org/10.20431/2454-9444.0601005

Copyright: (C) 2020 Authors. This is an open-access article distributed under the terms of the Creative Commons Attribution License, which permits unrestricted use, distribution, and reproduction in any medium, provided the original author and source are credited. 